\title{
HUMAN INTERACTION IN THE DIGITAL AGE: SOCIOMATERIAL PRACTICE ON FACEBOOK GROUP IN INDONESIA
}

\author{
Wulan Widyasari ${ }^{1}$ and Heidrun Allert ${ }^{2}$ \\ ${ }^{I}$ PhD Student at Institute of Education at Christian-Albrechts-Universität zu Kiel, Germany \\ Lecturer at Communication Department atUniversitas Muhammadiyah Yogyakarta \\ ${ }^{2}$ Professor at Institute of Education at Christian-Albrechts-Universität zu Kiel, Germany
}

\begin{abstract}
This paper analyzes the way of understanding and patterns of human interactions while using social media as constitutively entangled with the social practice and affordances of the technology that being carried out. Based on theoretical accounts we frame using media as socially and materially mediated. Using online ethnography, we see the different socio-material practice between the pro-LGBTQ and the anti-LGBTQ groups on Facebook regarding to the LGBTQ as a controversial issue in Indonesia. We analyse performative practices to see how the affordances of Facebook are enacted in co-producing the understanding of LGBTQ issues in both group. Although the issues discussed is the same issue in both Facebook groups, the socio-material practices that occur are different between the pro-LGBTQ and the anti-LGBTQ group. The data is collected from both groups using online observation in the period of March 2016 as the beginning of LGBTQ issues become a huge issue in Indonesia until July 2018 when LGBTQ was being criminalized by the Draft of the Criminal Code of Indonesia. As a result, we can see that the interaction pattern in both groups is different, depending on the issues that are being discussed and how the users perform the technology. The social practice is related to affordances and human interaction in a process that is constitutively entangled and performative.
\end{abstract}

\section{KEYWORDS}

Sociomaterial Practice, Affordances, Human Interaction, Facebook, LGBTQ

\section{INTRODUCTION}

Social media has changed the way people interact and communicate with others because of the digital technology being used as using media is socially and materially entangled. We can see it by looking at the sociomaterial practices occurring when groups create a collective understanding of a certain topic. According to Orlikowski (2009), the social and the material are considered to be inextricably related - there is no social that is not also material, and no material that is not also social. Furthermore, she also said that technology is here understood as material artifacts that are socially defined and socially produced, and thus as relevant only in relation to the people engaging with them. Thus, we can argue that the social practice and the material are constitutively entangled and that way we can understand knowledge process when people using technology. As Gherardi (2009) said, knowledge is therefore not only an activity situated in practices, but it is also an activity distributed between humans and non-humans. Objects, tools, and artifacts embody knowledge; they anchor practices in their materiality; they interrogate humans and are extensions of their memory.

It becomes interesting to see how human interaction using technology to produce knowledge when dealing with an controversial issue, such as LGBTQ. In Indonesia, the pros and cons of LGBTQ are widely discussed on social media. Until mid of 2018, the LGBTQ issues are heavily discussed regarding to the criminalization of LGBTQ in Indonesian Draft of the Criminal Code. It was started when the Indonesian Constitutional Court refused to try lawsuits about LGBTQ and adultery. Then, Indonesia's constitutional court rejects the petition for judicial review of some articles in Indonesian Draft of the Criminal Code, which regulate crime against decency, like adultery and LGBTQ. As a result of the rejection, the pros and cons of LGBTQ became a hot topic in the community. Namely Perkumpulan Arus Pelangi and AILA Indonesia are groups that are quite 
vocal in shouting LGBTQ issues. Both groups also have open Facebook groups dedicated to all Facebook users who are interested in gender and LGBTQ issues. The members of both groups were not recruited, every user who likes to join both groups and expressing their opinions are able to participate. Both group concern on LGBTQ issues, however they are on different position regarding to LGBTQ issues. Perkumpulan Arus Pelangi is a pro-LGBTQ group and AILA is an anti-LGBTQ group. Although both groups discuss the issue of LGBTQ, discussions are performed differently and affordances are enacted differently between them. They also perform different social practices taking account of the different affordances. We can see the example in Figure 1.
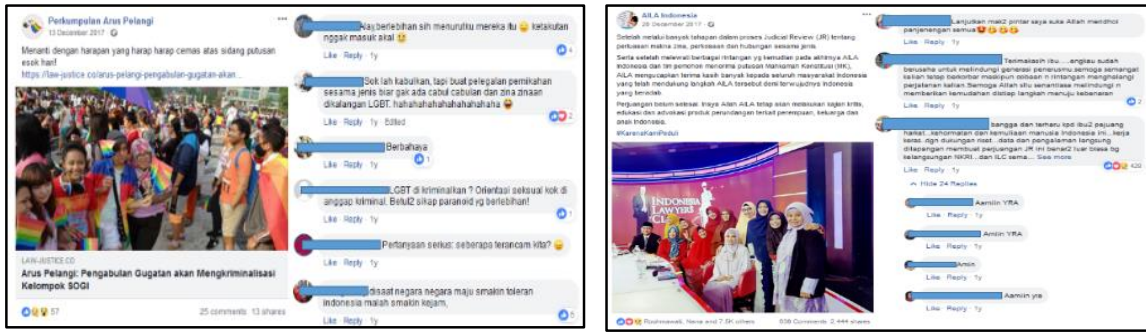

Figure 1. Perkumpulan Arus Pelangi and AILA Indonesia Facebook's post and discussions

The figure shows on how different is the interaction patterns of both group when dealing with LGBQ issues. In their Facebook's post, Perkumpulan Arus Pelangi waited for the result of judicial review from Indonesia's constitutional court regarding to Draft of the Criminal Code. The draft is important because if it was legalized, LGBTQ could be criminalized. In the comment, some users questioned why sexual orientation is criminalized and thought that it is a paranoid attitude. In contrast to Perkumpulan Arus Pelangi is a post from AILA Indonesia. The figure shows that AILA Indonesia accepts the constitutional court's decision and is grateful for the support of all parties. They also stated that their fight is not over yet. The comment shows a lot of support and prayer for AILA. Their support was more based on the argument of sake of the next generation. Taking account on how the affordances are enacted differently, Perkumpulan Arus Pelangi using a website link as an addition to their post while AILA Indonesia using a photo and hashtag to give illustration to their post.

As the basic assumption of our work is, there are different patterns in their interaction, we already see it in the comment section in figure 1. Furthermore, the use of hashtag \#KarenaKamiPeduli (because we care) on AILA Indonesia post is also interesting because the hashtag is used as an expression and not to use it as an structuring hashtag function, which is to other users easily find a post with a specific content. This was only an example to introduce what we found in our analysis. Based on this case, our article researches how human interactions dealing with a controversial issue like LGBTQ is constitutively entangled with affordances of Facebook. We analyse the interaction on Perkumpulan Arus Pelangi and AILA Indonesia pages using online ethnography to answer this following question: How is the way of understanding of LGBTQ issues and the patterns of Facebook interactions on different groups constitutively entangled with the social practice and Facebook affordances? To answer the question, firstly, we need to describe the understanding of sociomaterial practices.

\section{KEY CONCEPTS OF SOCIOMATERIAL PRACTICES}

In social theory, practice-theroetical approaches promulgate a distinct social ontology: the social is a field of embodied, materially interwoven collective practices centrally organized around shared practical understanding (Schatzki, 2001). In this regard, the value of practice theory is to ask questions about what people are doing and how they categorize what they are doing, avoiding the disciplinary or other preconceptions that would automatically read their actions as, say, "consumption" or "being-an-audience", whether or not that is how the actors see their actions (Couldry, 2004). Based on practice theory, not only the practice is different but also the understanding that appears in individual minds. That is, individual understanding is mediated by the practice that is being carried out. Furthermore, differences in understanding as a co-result of these different practices becomes more complex when dealing with technology. According 
to Orlikowski (2007), technology is understood to be emergent within the practices evolving and the different ways in which people engage with it. Furthermore, materiality is integral to organizing, positing that the social and the material are constitutively entangled in everyday life. A position of constitutive entanglement does not privilege either humans or technology (in one-way interactions), nor does it link them through a form of mutual reciprocation (in two-way interactions). In her other work, she also argued that technology is here understood as material artifacts that are socially defined and socially produced, and thus as relevant only in relation to people engaging with them (Orlikowski, 2009). Corradi and Gherardi (2010) also said, central to the practice perspective is acknowledgement of the social, historical and structural contexts in which knowledge is manufactured. The concept of practice allows researchers to investigate empirically how constituents and practical knowledge is continuously (re-)produced and how competence is built around a contingent logic of action.

Thus, also the reason why we need to look at how social media users post on their feeds because one social practice enacts technological affordances differently to other social practices. As Bardone said (2011), the notion of affordance is fundamental because it defines the nature of the relationship between an agent and its environment. Then, according to Boyd (2011), networked technologies introduce new affordances for amplifying, recording, and spreading information and social acts. These affordances can shape the public and how people negotiate them. While such affordances do not determine social practice, they can stabilize and destabilize core assumptions people make when engaging in social life. Here, we can understand affordances as tools or materials of a technology and its specific applications. For example, Facebook and Instagram have their own affordances, Facebook cannot be used the way we use Instagram. While in Facebook we can upload a post that contains text only, in Instagram we need to upload a photo and use the text as a caption. Furthermore, taking account of affordances for human interaction on Facebook, sociomaterial practice helps to understand how social practice is constitutively entangled with the Facebook affordances. As Bjørn and Østerlund said (2014), sociomateriality emphasizes the importance of material properties of artefacts and the changes in social practices caused by enacting such technologies. Sociomateriality points to the inseparability of the social and the material.

\section{RESEARCH METHOD}

The data of this research are being analyzed using online ethnography because, from a practice-theoretical perspective, the ethnographic field is constructed by the actions and expressions of the people we study and by the ethnographer's decisions about the connections s/he follows and forms; the field constantly evolves as the fieldwork progresses (Cruz and Ardevol, 2013). According to Hammersley (2006), ethnography is the tension between trying to understand people's perspectives from the inside while also viewing them and their behavior more distantly, in ways that may be alien (and perhaps even objectionable) to them. In the context of internet, Geertz (in Beneito-Montagut, 2011) stated that ethnography analyses human practices in the context of culture and now the internet is part of our culture, with meanings, symbols, and a 'system of conceptions expressed in symbolic forms by means of which users communicate, perpetuate and develop their knowledge about attitudes towards life'. Here, to conduct online ethnography, the everyday life of the social media ethnographer involves living part of one's life on the internet, keeping up to date with and participating and collaborating in social media discussions. This is not simply a virtual experience but is connected to the material world in important ways (Postill and Pink, 2012). Thus, in this research, the data is collected by conducting online ethnography to observe both Perkumpulan Arus Pelangi (pro-LGBTQ group) and AILA Indonesia (anti-LGBTQ group) Facebook pages. The observation data is gathered in the period of March 2016 as the beginning of LGBTQ issues become a huge issue in Indonesia until July 2018 when LGBTQ was being criminalized by the Draft of the Criminal Code of Indonesia.

We use key concepts of sociomateriality from Barad and Orlikowski that are formulated by Harris and Abedin in their work to analyze the data. Their key concepts are relationality practice, performativity practice, entanglement practice, sociomaterial assemblage practice and co-constitution practice (Harris and Abedin, 2015). We also take account of the recent affordances of Facebook that being carried out because platforms, affordances and algorithms are continuously developed. The affordances enacted are always changing, so are its use. As Hutchby (2001) stated, the affordances can shape the conditions of possibility associated with an action: it may be possible to do it one way, but not another. Furthermore, the use of 
affordances is socially mediated within situated practices. To analyze the data, we started with capturing the Facebook posts related to LGBTQ issues on Perkumpulan Arus Pelangi and AILA Indonesia, and saved it in word format. We have 189 pages from Perkumpulan Arus Pelangi and 255 pages from AILA Indonesia. Then we went through the data to see the pattern of discussion using online ethnography. After that, we took some examples of the pattern and put it into our paper. Our findings in this paper is only example of the repetitive pattern of discussion that we find in our data. Finally, in order to do this research, both admin of both groups gave permission to use their data for this research. The captured data from social media was also censored and paraphrased to protect the identity of the users. Both are done under the consent of General Data Protection Regulation (GDPR) article 6 (a) and (b), that said processing shall be lawful only if and to the extent that at least one of the following applies: (a) the data subject has given consent to the processing of his or her personal data for one or more specific purposes; (b) processing is necessary for the performance of a contract to which the data subject is party or in order to take steps at the request of the data subject prior to entering into a contract (https://gdpr.algolia.com/gdpr-article-6).

\section{FINDINGS: SOCIOMATERIAL PRACTICE IN UNDERSTANDING LGBTQ ISSUES}

When discussing the LGBTQ issue, the different perspectives between Perkumpulan Arus Pelangi and AILA Indonesia as discussed on facebook pages can be explained as sociomaterial practices of both groups that are s constitutively entangled with the Facebook affordances. First, we can see it from the relationality practice that is being carried out. Relationality practice means online communities exist in relation to other assemblages. That is, within an online community, common interest unites agents, whereas across communities, differences in practices (such as participant needs) will create boundaries and potential conflict (Harris and Abedin, 2015). We can see the example in figures 2.
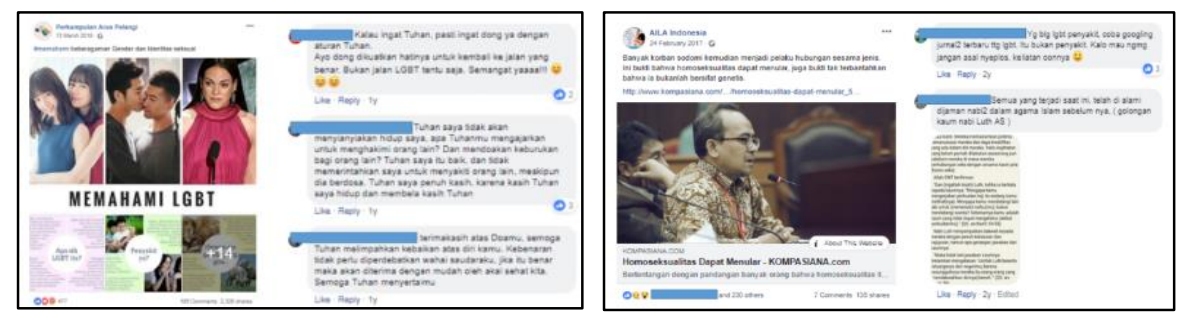

Figure 2. Perkumpulan Arus Pelangi and AILA Indonesia Facebook's post and comment section

In term of relationality practice, we found dominant interaction patterns from both groups. Perkumpulan Arus Pelangi has "LGBTQ is not a disease" as a pattern, which means LGBTQ is just ordinary human being. Figure 2 shows how Perkumpulan Arus Pelangi built narratives about LGBTQ when they used photos and info graphics to explain LGBTQ-related issues such as explaining LGBTQ notions, providing prove about LGBTQ are not diseases, giving examples of how animals also like same-sex relationship and so on. The post explained LGBTQ issues that are often discussed by the Indonesian community. In addition to this post, they also consistently builds narratives with facts that support LGBTQ, such as a post about the existence of gay priests in South Africa, how UK government vows to end practice of gay conversion therapy, an explanation of WHO views that state LGBTQ is not a disease and many others. These posts are consistent practices to create the pattern of discussion in the group so that they have common interest regarding to LGBTQ issues. Furthermore, in the comment section, we can see what happens when there are comments that are not in accordance with the common interest of the group. There was seen a user who stated that LGBTQ was not the right way because it was not following God's rules. The reaction that arose in response to this statement was a refusal, like when other users questioned why God judged others and wrote that God actually taught love and did not hurt others even though they sinned. In addition, the user also prayed that god will always be bestowed and suggested that the truth should not be debated because truth can always be accepted by common sense. From here, we can know the pattern of discussing LGBTQ issues on Perkumpulan Arus Pelangi group is using research and news about LGBTQ. The pattern of these rules is 
shown on many of their posts and discussion, mostly they refuse to accept opinions that are not based on facts. They also rarely use a religious perspective and when they do, they say it in universal language. Furthermore, we can see the affordances enacted on their post is infographic in the form of photo to explain about LGBTQ.

Meanwhile, the relationality practice carried out by AILA Indonesia is in stark contrast to Perkumpulan Arus Pelangi in understanding LBGTQ issues. Here, AILA Indonesia has "LGBTQ is a disease and threat" as a pattern, which means LGBTQ is dangerous for humanity. Figure 2 shows AILA Indonesia's post about many victims of sodomy become homosexuals proving that homosexuality is contagious. They consistently builds anti LGBTQ narratives by selecting harsh words to mention LGBTQ such as perpetrator, threats, sexual deviations and other similar words in their posts. In addition, they have also consistently posted links that show the reason why they resistance to LGBTQ such as an explanation of LGBTQ as a Western secularism that is incompatible with Indonesia as religious country, news of the existence of gay prostitution that endangers the next generation, argumentation about natural disasters as a punishment from God because of LGBTQ and so on. The selection of these posts builds a narrative so that the members of AILA Indonesia have a common interest about how LGBTQ is a concern that needs to be addressed because it is contrary to their religion. Then, in the comment section, we can see the practice when a user disagrees with their understanding. There was seen a user suggest that people who said that LGBTQ was a disease need to find the latest journals about LGBTQ. Then, other users responded to that statement by including the Koran verses about the story of Prophet Lot and LGBTQ. These comments indicate that differences in views about LGBTQ lead to restrictions for discussion. They have discussion pattern that say LGBTQ is outsider perspective and undermines the morale of the Indonesian people. Their basic rule of argumentation is the Islamic perspective, so Islamic verses can be easily found in their discussions. This Islamic verses also shown on many of their posts, like when they explain about earthquake and blame the LGBTQ because of Prophet Lot story in Koran. Furthermore, we also can see the difference affordances that being enacted by AILA Indonesia. On their Facebook, AILA Indonesia is using a website link to explain the reason why LGBTQ is contagious and on their comment section, one of the user use a photo to explain their opinion about LGBTQ.

Second, we can see sociomaterial practice from the performativity practice. Perfomativity practice means relationships between community participants and social media technology are never fixed. Instead, the socio-material assemblage (online community) emerges from practice and defines how to practice. It is in the act of participating that the relation (between the participant and the social media technology) is defined, and each participatory act (re)produces (or performs) the socio-material practice (Harris and Abedin, 2015). Here, we found dominant interaction patterns from both groups. Perkumpulan Arus Pelangi has "diversity" as a pattern, which means LGBTQ as one of social diversity. In contrast, AILA Indonesia has "Islamic perspectives" as a pattern, which means LGBTQ must be seen in term of Islamic values. We can see examples of the differences in performativity practice conducted by Perkumpulan Arus Pelangi and AILA Indonesia. The religious template in AILA Indonesia remains the most dominant pattern, in contrast to Perkumpulan Arus Pelangi which uses universal value templates more often. The difference in performativity practice certainly forms different participation actions within the two groups where in Perkumpulan Arus Pelangi the argument about religion is a matter of mockery and sarcasm, but at AILA Indonesia is the main foundation that strengthens their perspective. Based on our observations, the member of Perkumpulan Arus Pelangi has discussion pattern when showing their support to LGBTQ, that is using the diversity and equality perspective, like the use of research data. In the other side, AILA Indonesia has different discussion pattern, that is using Islamic perspective when showing their rejection to the LGBTQ issues, like the use of many Arabic words in expressing their concern in the discussion. Furthermore, both groups also use different affordances. We can see on the use of rainbow sticker to show a support to LGBTQ in Perkumpulan Arus Pelangi and the use of writing text on AILA Indonesia comment's section.

Third, we can see the sociomaterial practice from the entanglement practice conducted by both groups. Entanglement practice means the material and the social emergently produce one another, as people, entangled with a variety of social media-based technologies, participate in online communities in the carrying out of their daily social practices (Harris and Abedin, 2015). Perkumpulan Arus Pelangi has "creativite features" as a pattern, which means they use creative and innovative way to spread their messages. In contrast, AILA Indonesia has "conservative features" as a pattern, which means they use traditional way to post their messages. For example, we can see how they uses info graphic images to explain the impact of negative media coverage on the LGBTQ community. Other than that, they also uses various Facebook's features in a creative way. In addition to using infographics, Perkumpulan Arus Pelangi also uses video 
feature to post songs about LGBTQ, films and profiles of inspiring LGBTQ people. Whereas AILA Indonesia prefers their posts in serious approach such as live video of the RKUHP trial in the Constitutional Court. AILA Indonesia never uses info graphics and mostly uses live video feature that contain dialogues and presentations from people who support AILA Indonesia. Perkumpulan Arus Pelangi used various Facebook affordances to update their posts on their page, meanwhile AILA Indonesia mostly use live video and writing text on their page. These enactments of affordances are seen throughout on both pages posts.

Fourth, we can see the sociomaterial practice from the sociomaterial assemblage practice conducted by bothe groups. Sociomaterial assemblage practice means an online community is a composite and shifting assemblage of the material and social, which change over time as those involved participate in online community activities to provide meaning, to exercise power, and to legitimate actions (Harris and Abedin, 2015). We found dominant interaction patterns in both groups when we see how users deal with legitimate action between humans and technology, such as "deleting comment". We can see the examples in figure 3.
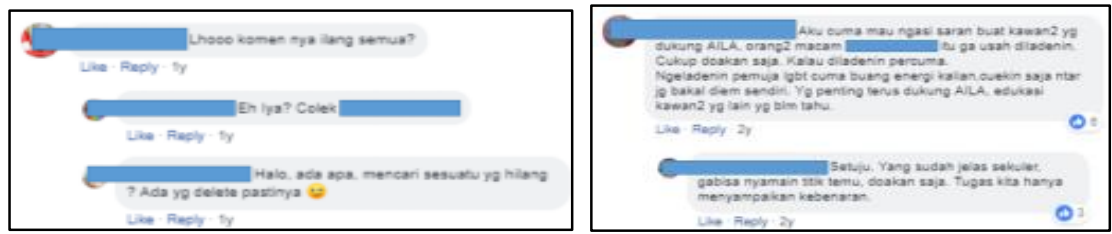

Figure 3. Facebook comments on Perkumpulan Arus Pelangi and AILA Indonesia post

Figure 3 shows the user interactions in the comment section of Perkumpulan Arus Pelangi and AILA Indonesia page. There are users in Perkumpulan Arus Pelangi who asks why many comments are missing. A user even feels confident to say that someone deleted those comments. This shows two things. First, when deleting a comment on Facebook, other comments under the deleted-comment will also be deleted. Second, a legitimate action to delete a comment in Facebook page is for both the administrator of the page and the user who posted the comment itself. In AILA Indonesia, we can see the interaction of users who discusses the need not to respond to comments from LGBTQ supporters because they have secular view. A user wrote a reason for ignoring the comments of the LGBTQ supporters because it only wastes their energy, while other users argue to pray for the LGBTQ supporters and keep telling the truth. This shows the legitimate action of the user can influence other users to comment on Facebook's discussions, even though this action does not have the absolute power to delete existing comments, the privilege is still in the hands of group's administrator. Figure 3 show how the ability to delete a comment on Facebook is a special characteristic of Facebook's affordances because of its ability to delete the following comment in sequence.

Finally, we can see the sociomaterial practice from the co-constitution practice. Co-constitution practice means the material (media technology) and the social are mutually constituted and inseparable. Structures and processes of an online community are enacted and emergent as participants draw upon communication features in their situated practices (Harris and Abedin, 2015). Here, we found dominant interaction patterns in both groups when we see how users use hashtags in their posts. Perkumpulan Arus Pelangi has "hashtags as campaign" pattern, which means they use hashtags for specific pupose. AILA Indonesia has "hashtag as emotion" pattern, which means they use hashtags to emphasize certain emotion. For example, we can see how Perkumpulan Arus Pelangi uses certain hashtags that are used to highlight certain issues such as the \#IDAHOT2016 to discuss LGBTQ issues related to International Day Against Homophobia Biphobia and Transphobia in 2016. Through the hashtag, Perkumpulan Arus Pelangi sought to call attention to LGBTQ issues that they are fighting for and point to further context, communities and informationspheres. Whereas in AILA Indonesia, there are users using the hashtag like \#elusdada only to express their concern for LGBTQ issue. The use of hashtag is different from the use of hashtags conducted by Perkumpulan Arus Pelangi because the hashtag that being used is not intended for campaigns or easy access to look for certain information but as an expression of feelings. The use of hashtags also means structures and processes of affordances are enacted and emergent as Facebook users draw upon Facebook features in their situated practices. From the observation, Perkumpulan Arus Pelangi used a hashtag as tool of spreading information, and on the other hand, AILA Indonesia used a hashtag as affirmation of the statement that was being made.

From the data that has been described, we can say that all the practices are always related to co-constitution practice. Here, affordances can be seen as a force for co-constituting practice. Most relevant affordances in performing practices in these two groups are website link, photo, video, live video, sticker, hashtag and deleting comments. The very powerful one is the deleting comments because it is a legitimate action that can produce a different meaning and it cab even eliminate its meaning of the existing discussions. 


\section{DISCUSSION}

Based on the data presented, it shows that interactions in social media related to the technologies co-produce the social practice. Producing an understanding of the issue of LGBTQ is socially and materially mediated. Facebook affordances that are shown, such as video feature or hashtags can provide different interaction meanings between two different groups. These affordances also helped shaping the different understanding of the LGBTQ issue between Perkumpulan Arus Pelangi and AILA Indonesia as they formed different narratives towards LGBTQ issues using different features on Facebook. Perkumpulan Arus Pelangi use the Facebook affordances to give meaning how LGBTQ is only sexual diversities that no difference with heterosexual and to give understanding about LGBTQ by using creative content like info graphics and music video. Meanwhile AILA Indonesia use the Facebook affordances in more affirmative way to create understanding that LGBTQ is a threat to Indonesian society. Of course, these differences in using Facebook affordances create a different practice in both groups. As Gherardi (2009) said, knowledge is therefore not only an activity situated in practices, but it is also an activity distributed between humans and non-humans. Objects, tools, and artifacts embody knowledge; they anchor practices in their materiality; they interrogate humans and are extensions of their memory. Practice is always related to the technology's affordances - but not in a deterministic manner. As we can see from the data, for example, when there is power relation take its roles by deleting a post or a comment, the context of the interaction change and we lost the understanding of the whole interaction. We can conclude that the most important Facebook affordances on both groups is the deleting tool because it can create different interaction and meaning of the discussion. This deleting-comment can produce different result of the discussion because it could stop the discussion.

Finally to answer the research question, we can say that the pattern of interaction between both groups are indeed different and it is related on how users deal with Facebook affordances as a social practice. The two groups co-produce different culture and pattern on understanding LGBTQ issues. We can also agree with van Dijk and Rietveld, although much in the behavior setting remains the same, in the newly unfolding socio-material context many affordances also change. In short, parts of the socio-material environment and the resulting behavior patterns are continuously re-arranged and reconfigured and other affordances enter the situation and dissipate as the departure time of the train approaches or the coffee is finished (van Dijk and Rietveld, 2017). It means, even though Facebook has affordances that can be used by any user throughout Facebook platform, however users can create different meaning and interaction based on the different socio-material practice that being carried out. As Costa (2017) said, practice theories can enable media scholars to move away from the limits imposed by the affordance and algorithm paradigm, and can enable them to grasp the varieties of possible uses of social media.

\section{CONCLUSION}

Dealing with technology in social life can create a different meaning of human interaction. It becomes indeed relevant when we deal with controversial issue, such as LGBTQ in Indonesia, where there is pros and cons as a political issue. The understanding of LGBTQ between the two different groups is different. Knowing is constitutively entangled with the socio-material practices and the technological affordances. As Kimmerle, Moskaliuk, Oeberst and Cress (2015) said, community as a whole develops and constructs new knowledge while the community members also individually advance and refine their own knowledge. So individual learning and collaborative knowledge construction are interdependent and occur simultaneously. Furthermore, when we analyze the socio-material practices we cannot exclude the power issues between humans and Facebook's technology that can shape human interactions on both groups. This power issue is related to how users can take control and action when using Facebook affordances. According to Boyd (2011), networked technologies introduce new affordances for amplifying, recording, and spreading information and social acts. These affordances can shape the public and how people negotiate them. Finally, the limitation of this research is that we only analyze the socio-material practice on Facebook pages and did not analyze on the individual Facebook accounts. Therefore, it needs future research to explain the difference of interaction pattern between Facebook page and individual Facebook account. 


\section{ACKNOWLEDGEMENT}

This work was supported by Deutscher Akademischer Austauschdienst e.V. (DAAD) - Indonesian German Scholarship Program.

\section{REFERENCES}

Bardone, E. (2011). Seeking Chances (From Biased Rationality to Distributed Cognition. Berlin: Springer.

Beneito-Montagut, R. (2011). Ethnography goes online: towards a user-centred methodology to research interpersonal communication on the internet. Qualitative Research 11(6) 716-735.

Bjørn, P and Østerlund, C. (2014). Sociomaterial-Design, Bounding Technologies in Practice. Switzerland: Springer.

Boyd, D. (2011). Social Network Sites as Networked Publics (Affordances, Dynamics, and Implications). In Zizi Papacharissi (ed.). A Networked Self (Identity, Community, and Culture on Social Network Sites). New York: Routledge.

Caliandro, A. (2017). Digital Methods for Ethnography: Analytical Concepts for Ethnographers Exploring Social Media Environments. Journal of Contemporary Ethnography 1-28.

Costa, E. (2017). Social Media as Practices: an Ethnographic Critique of 'Affordances' and 'Context Collapse, Working papers for the EASA Media Anthropology Network's 60 ${ }^{\text {th }}$. Retrieved May 25, 2019, from: http://www.media-anthropology.net/file/costa_socialmedia_as_practice.pdf

Couldry, N. (2004). Theorising Media as Practice. Social Semiotics Volume 14 Number 2, August 2004.

Corradi, Gessica \& Gherardi, Silvia. 2010. Through the practice lens: Where is the bandwagon of practice-based studies heading? Management Learning 41(3) 265-283.

General Data Protection Regulation. Retrieved May 20, 2019, from: https://gdpr.algolia.com/gdpr-article-6.

Gherardi, S. (2009). "Knowing and learning in practice-based studies: an introduction", The Learning Organization Vol. 16 Issue: 5, pp.352-359.

Hammersley, M. (2006). Ethnography: problems and prospects. Ethnography and Education, 1:1, 3-14.

Harris, G and Abedin, B. (2015). Participating or Not Participating? A Sociomaterial Perspective of the Embeddedness of Online Communities in Everyday Life. Australasian Conference on Information Systems, Adelaide.

Hutchby, I. (2001). Technologies, Texts and Affordances. Sociology Vol. 35, No. 2, pp. 441-456.

Kimmerle, J, Moskaliuk, J, Oeberst, A and Cress, U. (2015) Learning and Collective Knowledge Construction With Social Media: A Process-Oriented Perspective. Educational Psychologist, 50:2, 120-13.

Orlikowski, W. J. (2007). Sociomaterial Practices: Exploring Technology at Work. Organization Studies 28(09): $1435-1448$.

Orlikowski, W. J. 2009. "The sociomateriality of organisational life: considering technology in management research." Cambridge Journal of Economics 34 (2009): 125-141.

Postill, J. and Pink, S. (2012). Social Media Ethnography: The Digital Researcher in A Messy Web. Media International Australia incorporating Culture and Policy 145 (145): 123-134. November 2012.

Schatzki, T. R. (2001). 'Introduction: Practice Theory', In: Schatzki, T. R., K. Knorr Cetina and E. von Savigny (eds) 2001. The Practice Turn in Contemporary Theory, London: Routledge, pp. 1-14.

van Dijk, Ludger \& Rietveld, Erik. 2017. Foregrounding Sociomaterial Practice in Our Understanding of Affordances: The Skilled Intentionality Framework. Front. Psychol. 7:1969. 